\title{
A pilot controlled trial of insulin-like growth factor-1 in children with Phelan-McDermid syndrome
}

\author{
Alexander Kolevzon 1,2,3,4,5,10*, Lauren Bush ${ }^{1,4,10}$, A Ting Wang 1,2,4,6,10, Danielle Halpern ${ }^{1,4,10}$, Yitzchak Frank ${ }^{1,4,5,7,10}$, \\ David Grodberg ${ }^{1,4,10}$, Robert Rapaport ${ }^{5,9,10}$, Teresa Tavassoli ${ }^{1,4,10}$, William Chaplin ${ }^{11}$, Latha Soorya ${ }^{12}$ \\ and Joseph D Buxbaum ${ }^{1,2,3,4,6,8,10}$
}

\begin{abstract}
Background: Autism spectrum disorder (ASD) is now understood to have multiple genetic risk genes and one example is SHANK3. SHANK3 deletions and mutations disrupt synaptic function and result in Phelan-McDermid syndrome (PMS), which causes a monogenic form of ASD with a frequency of at least $0.5 \%$ of ASD cases. Recent evidence from preclinical studies with mouse and human neuronal models of SHANK3 deficiency suggest that insulin-like growth factor-1 (IGF-1) can reverse synaptic plasticity and motor learning deficits. The objective of this study was to pilot IGF-1 treatment in children with PMS to evaluate safety, tolerability, and efficacy for core deficits of ASD, including social impairment and restricted and repetitive behaviors.
\end{abstract}

Methods: Nine children with PMS aged 5 to 15 were enrolled in a placebo-controlled, double-blind, crossover design study, with 3 months of treatment with IGF-1 and 3 months of placebo in random order, separated by a 4-week wash-out period.

Results: Compared to the placebo phase, the IGF-1 phase was associated with significant improvement in both social impairment and restrictive behaviors, as measured by the Aberrant Behavior Checklist and the Repetitive Behavior Scale, respectively. IGF-1 was found to be well tolerated and there were no serious adverse events in any participants.

Conclusions: This study establishes the feasibility of IGF-1 treatment in PMS and contributes pilot data from the first controlled treatment trial in the syndrome. Results also provide proof of concept to advance knowledge about developing targeted treatments for additional causes of ASD associated with impaired synaptic development and function.

\section{Background}

Autism spectrum disorder (ASD) is currently a diagnosis established by behavioral criteria but its etiology resides in complex genetics, and many distinct genetic risk genes have been identified as causal. One such example is the SHANK3 gene located on the terminal end of chromosome 22q where loss of one copy (haploinsufficiency) of SHANK3 causes a monogenic form of ASD with a

\footnotetext{
* Correspondence: alexander.kolevzon@mssm.edu

'Seaver Autism Center for Research and Treatment, Icahn School of Medicine at Mount Sinai, One Gustave L Levy Place, Box 1230, New York, NY 10029, USA

${ }^{2}$ Friedman Brain Institute, New York, NY, USA

Full list of author information is available at the end of the article
}

frequency of at least $0.5 \%$ of ASD cases [1-4]. The SHANK3 gene codes for a protein that plays a critical role in synaptic function by scaffolding the postsynaptic density of glutamatergic synapses [5] and its loss is sufficient to cause Phelan-McDermid syndrome (PMS) [6,7]. PMS is characterized by significant intellectual disability (ID), severely delayed or absent language, and ASD. Affected individuals also suffer from a heterogeneous array of dysmorphic and medical features, including increased risk of seizures, recurring infections, hypotonia, renal disease, and gastroesophageal reflux [8-17]. While PMS accounts for a relatively small proportion of ASD cases, the SHANK3 pathway is relevant to many forms of ASD 
because different genetic causes of ASD converge on several common pathways, including SHANK3 [18,19].

Using Shank3-deficient mice, deficits in synaptic function and plasticity have been shown using electrophysiological measures [20]. Behaviorally, Shank3-deficient mice display motor deficits, less social sniffing and reduced ultrasonic vocalizations as compared to wildtype controls [20,21]. Insulin-like growth factor-1 (IGF-1) has been studied in this mouse, as well as in human neuronal models of PMS, and was found to reverse synaptic and behavioral deficits [21]. Importantly, IGF-1 is also effective in reversing phenotypic changes in human neuronal models of Rett syndrome [22], providing additional evidence that this pathway may be a target in diverse forms of ASD. These data are promising and provide preclinical evidence that IGF-1 may produce disease-modifying effects in subjects with PMS or Rett syndrome. Recent evidence also provides preliminary support of efficacy with IGF-1 in children with Rett syndrome [23].

IGF-1 is a commercially available compound that crosses the blood-brain barrier (BBB) and has beneficial effects on synaptic development by promoting neuronal cell survival, synaptic maturation, and synaptic plasticity $[23,24]$. IGF-1 enters the brain from the circulation where it is released mainly by the liver upon growth hormone stimulation. Blood-borne IGF-1 is found in the central nervous system (CNS) where it promotes brain vessel growth [25], neurogenesis, and synaptogenesis [26]. The mechanisms that trigger IGF-1 entry through the BBB are proposed to occur by diffusible messengers released in areas of neuronal activity which lead to cleavage of IGF binding protein-3 (IGFBP-3) to increase free IGF-1 and allow passage of circulating IGF-1 into the CNS [27]. The recent IGF-1 study in Rett syndrome examined its pharmacokinetic profile in human subjects and found that IGF-1 reached the CNS compartment as demonstrated by significantly increased cerebrospinal fluid levels after treatment [23]. However, the precise mechanisms by which IGF-1 exerts its effects on the CNS remains an active area of study.

IGF-1 is currently approved by the Food and Drug Administration (FDA) for the treatment of short stature due to primary IGF-1 deficiency (Laron's Dwarfism). There have been no controlled treatment trials in PMS to date and this study was designed to evaluate the safety, tolerability, and efficacy of IGF-1 versus placebo in children with PMS targeting core domains of ASD. Specifically, social deficits and repetitive behaviors were measured using the Aberrant Behavior Checklist-Social Withdrawal (ABC-SW) subscale as the primary outcome measure [28] and the Repetitive Behavior Scale-Revised (RBS-R) as a secondary outcome [29].

\section{Methods}

All subjects were recruited under an Institutional Review Board (IRB) approved protocol as part of ongoing studies in PMS at the Seaver Autism Center for Research and Treatment at the Icahn School of Medicine at Mount Sinai and parents/guardians provided informed consent. Treatment followed a randomized, placebo-controlled, crossover format with 12 weeks in each treatment arm (IGF-1 and placebo), separated by a 4-week wash-out phase (ClinicalTrials.gov Identifier: NCT01525901). This was a pilot study in a rare disorder, PMS, and sample size and analyses were defined a priori. Multiple outcome measures are being collected as part of a larger ongoing clinical trial with IGF-1 in PMS but pilot data from the safety measures, and main primary and second outcomes have been analyzed to date and are presented herein.

\section{Inclusion criteria}

This pilot recruited 9 children between 5 and 15 yearsold with PMS and confirmed to have SHANK3 deletions or mutations based on chromosomal microarray or highthroughput or targeted sequencing. All subjects were on stable medication regimens for at least 3 months prior to enrollment.

\section{Exclusion criteria}

Cases were excluded if any of the following were applicable: 1) closed epiphyses; 2) active or suspected neoplasia; 3) intracranial hypertension; 4) hepatic insufficiency; 5) renal insufficiency; 6) cardiomegaly/valvulopathy; 7) allergy to IGF-1;8) patients with comorbid conditions deemed too medically compromised to participate.

\section{Drug administration}

IGF-1 (Increlex; Ipsen Biopharmaceuticals, Inc) is an aqueous solution for injection containing human insulinlike growth factor-1 (rhIGF-1) produced by recombinant DNA technology. Placebo consisted of saline prepared in identical bottles by the research pharmacy at Mount Sinai. We received an Investigational New Drug exemption from the Food and Drug Administration (\#113031) to conduct this trial in children with PMS. Based on the package insert for Increlex, dose titration was initiated at $0.04 \mathrm{mg} / \mathrm{kg}$ twice daily by subcutaneous injection, and increased, as tolerated, every week by $0.04 \mathrm{mg} / \mathrm{kg}$ per dose to a maximum of $0.12 \mathrm{mg} / \mathrm{kg}$ twice daily. This titration was justified based on our preclinical data, which indicated that $0.24 \mathrm{mg} / \mathrm{kg} /$ day is effective in reversing electrophysiological deficits whereas $0.12 \mathrm{mg} / \mathrm{kg} /$ day was not as effective [21]. We aimed to reach the therapeutic dose as quickly as is safe and tolerated in order to allow maximum time for clinical improvement. Doses could be decreased according to tolerability by $0.04 \mathrm{mg} / \mathrm{kg}$ per dose. Medication was administered twice daily with meals, and preprandial glucose monitoring was performed by parents prior to each injection throughout the treatment period. Parents were carefully trained 
in finger stick monitoring, symptoms of hypoglycemia, and medication administration.

\section{Outcome measures}

Efficacy measurements were taken at baseline of each treatment phase, and at weeks 4,8 , and 12 of each treatment phase. The $A B C$ is a rating scale used to monitor an array of behavioral features, including social withdrawal (i.e., Lethargy subscale). The ABC-SW subscale was chosen a priori as the primary outcome measure because it is well validated in both ID and ASD patients and is currently accepted as an appropriate outcome measure within the field of pediatric psychopharmacology research. In addition, preliminary data suggest that the $\mathrm{ABC}$ accurately reflects ASD-related deficits in PMS. Repetitive behavior was measured using the RBS-R, which has also been previously validated as a measurement tool in ID and ASD populations. Safety, tolerability, and adverse events (AEs) were measured throughout the trial during monitoring visits and phone calls using an adapted semi-structured interview, the Safety and Monitoring Uniform Report Form (SMURF) every 2 weeks, and extensive clinical and laboratory assessments every 4 weeks. AEs were documented with respect to severity, duration, management, relationship to study drug, and outcome.

\section{Data analysis}

This trial used a randomized crossover design; thus, order (phase) of assessment is nested (repeated) within treatment and treatment is nested within subjects. Given the small sample size, we considered several analytic strategies and selected a fully within-subject, repeated-measures design. To conform to intent-to-treat principles, we used mixed effects regression models so that participants missing observations would be included in the analysis (full information maximum likelihood estimation). Treatment was dummy coded as $0=$ placebo and $1=$ control and time coded naturally as weeks $(0,4,8$, and 12$)$. In this analysis, the primary focus was time by treatment interaction, which estimates the differential change in the two treatments on the outcome measures. Because of the small sample size, we used a variance components intercept only model for the random effect variation. We then added 'phase' as another repeated factor to examine the effect of order through a three-way interaction analysis.

\section{Results}

A total of 9 children and adolescents ( 6 females and 3 males) were screened based on the established diagnosis of PMS and all 9 were randomized to treatment order. Subjects ranged in ages from 5 to 15 years old at the time of entry into the study $(X=8.6$ years; $S D=4.0)$. At baseline, the mean ABC-SW subscale score was 16.9 $(\mathrm{SD}=8.7)$ for all subjects and the mean RBS-R Total score was $32.1(\mathrm{SD}=23.5)$. Cognitive abilities were evaluated with the Mullen Scales for Early Learning [30] or the Leiter International Performance Scale-Revised [31] and adaptive functioning with the Vineland Adaptive Behavior Scales, Second Edition [32]. All participants met criteria for ID based on mental age equivalent scores on IQ measures and adaptive behavior composite scores (see Table 1). The Leiter was the preferred measure of nonverbal IQ in our sample given the potential to calculate standard scores in this age range. However, only two of nine participants had the pre-requisite skills to participate in a Leiter administration based on the ability to make a two-part discrimination, sit, and attend. For the remaining 7 of 9 participants, we used the Mullen despite the fact that the upper end of the Mullen standardization sample is 68 months. All subjects met criteria for ASD according to expert clinical consensus and results from the Autism Diagnostic Observation Schedule-Generic [33], the Autism Diagnostic Interview-Revised (ADI-R; [34]), and the Diagnostic and Statistical Manual for Mental Disorders-5 [35].

Because this was a small pilot trial, our primary focus was on safety. IGF-1 was generally well tolerated and there were no serious adverse events (SAEs) (see Table 2). The most common side effects during the IGF-1 treatment phase were sleep disturbance $(\mathrm{N}=7)$; hypoglycemia $((<50 \mathrm{mg} / \mathrm{dL})(7$ occurrences; $\mathrm{N}=5))$, constipation $(\mathrm{N}=4)$, increased appetite $(\mathrm{N}=4)$, and mood changes or increased irritability $(\mathrm{N}=4)$. Other less common AEs 'possibly' or 'probably related' to IGF-1 and worth noting included decreased appetite $(\mathrm{N}=2)$, increased urinary frequency $(\mathrm{N}=1)$, hair loss $(\mathrm{N}=1)$, rash $(\mathrm{N}=1)$, and soft tissue swelling of the nose $(\mathrm{N}=1)$. The rash resolved upon discontinuing IGF-1 and did not recur upon re-challenge. The soft tissue swelling also resolved upon completion of the treatment phase without intervention or dose adjustment. One

\section{Table 1 Baseline demographic characteristics}

\begin{tabular}{cccc}
\hline Subject & $\begin{array}{c}\text { Chronological } \\
\text { age (months) }\end{array}$ & $\begin{array}{c}\text { Estimated mental } \\
\text { age equivalent } \\
\text { (months) }\end{array}$ & $\begin{array}{c}\text { Vineland adaptive } \\
\text { behavior scale } \\
\text { composite } \\
\text { standard score }\end{array}$ \\
\hline 1 & 177.4 & 8.5 & 29 \\
2 & 103.7 & 10.3 & 47 \\
3 & 66.3 & 11.3 & 52 \\
4 & 64.6 & 12.3 & 43 \\
5 & 109.7 & a36 & 61 \\
6 & 91.8 & 7 & 50 \\
7 & 172.7 & 30.5 & 31 \\
8 & 71.1 & 31 & 51 \\
9 & 61.8 & 9.3 & 45 \\
\hline
\end{tabular}

a Denotes scores from the Leiter International Performance Scale-Revised; all other scores were based on the Mullen Scales for Early Learning. 
Table 2 Adverse events

\begin{tabular}{|c|c|c|}
\hline Adverse events & IGF-1 & Placebo \\
\hline Constipation & 4 & 3 \\
\hline Sedation & 1 & 0 \\
\hline Decreased appetite & 2 & 3 \\
\hline Periobital/facial swelling & 1 & 0 \\
\hline Diarrhea & 1 & 2 \\
\hline URTI $\left.\right|^{a}$ & 5 & 5 \\
\hline Sleep Disturbance & 7 & 2 \\
\hline Increased appetite & 4 & 0 \\
\hline Mood changes/irritability & 4 & 2 \\
\hline Increased thirst & 1 & 0 \\
\hline Increased phlegm & 1 & 0 \\
\hline Teeth grinding & 1 & 0 \\
\hline Cough & 1 & 2 \\
\hline Hand flapping & 1 & 0 \\
\hline Increased bowel movements & 1 & 0 \\
\hline Increased chewing/biting & 1 & 0 \\
\hline Decreased visual acuity & 1 & 0 \\
\hline Lethargy/decreased energy & 1 & 1 \\
\hline Cooler body temperature/sweating & 1 & 0 \\
\hline Runny nose/congestion & 1 & 1 \\
\hline Gait changes/fell & 1 & 2 \\
\hline Stomach virus & 1 & 1 \\
\hline Anxiety & 0 & 2 \\
\hline Increased urine frequency & 2 & 0 \\
\hline Fever & 3 & 3 \\
\hline Increased energy & 1 & 0 \\
\hline Gagging & 1 & 0 \\
\hline Increased thirst & 0 & 1 \\
\hline Conjunctivitis & 1 & 0 \\
\hline Erythema/swollen eyes & 1 & 0 \\
\hline Vomiting & 1 & 1 \\
\hline Rash & 3 & 0 \\
\hline Nose swelling & 1 & 0 \\
\hline Warmer body temperature & 1 & 0 \\
\hline Hair loss & 1 & 0 \\
\hline Increased aggression & 1 & 0 \\
\hline Hypoglycemia $^{b}$ & 7 & 3 \\
\hline
\end{tabular}

patient had to be discontinued because they developed an upper respiratory tract infection requiring antibiotics that led to gastrointestinal symptoms, constipation, and decreased appetite and they could not adequately sustain their glycemic state to tolerate treatment. At the early termination visit, the patient was fully recovered without sequelae. No other patients required dose adjustments during the trial. Many of the same AEs were likely to occur among patients during the placebo phase, including hypoglycemia ( 3 occurrences; $\mathrm{N}=2$ ), albeit less frequently; significantly more AEs were reported when patients were taking IGF-1 than placebo $(P=0.0015)$. There were no significant changes in growth parameters, including height, weight, head circumference, or bone age over the course of the trial.

In terms of efficacy, when participants received IGF-1 they showed significant improvement as compared to when they were on placebo (see Figures 1 and 2). There was a significant two-way time $\mathrm{x}$ group interaction across both phases on the ABC-SW subscale $(\mathrm{N}=9 ; \mathrm{t}=-2.107$; $P=0.040$ ). Importantly, when 'phase' (order) was added as a third variable, the three-way interaction of group $x$ time $\mathrm{x}$ phase was not significant. This indicates that the time $\mathrm{x}$ group interaction is not significantly different as a function of treatment order and the two-way interaction is a valid reflection of the drug effect. Inspection of a longitudinal plot of the data suggested that the drug condition showed improvement in both phases whereas the placebo group showed little change in either phase.

However, participants assigned to IGF-1 at phase 1 had a higher baseline ABC-SW value at phase 1 than the placebo participants. Given the small sample size, this disparity is not surprising despite randomization. To account for this disparity we controlled for phase $1 \mathrm{ABC}$ $\mathrm{SW}$ baseline values and the time $\mathrm{x}$ treatment interaction remained significant $(\mathrm{N}=9 ; \mathrm{t}=-2.151 ; P=0.036)$. Analyses were performed on the other $\mathrm{ABC}$ subscales and results were not statistically significant (Irritability: $\mathrm{t}=-0.839$, $P=0.405$; Motor Stereotypies: $\mathrm{t}=-0.240, \quad P=0.811$; Hyperactivity: $\mathrm{t}=-0.954, P=0.344$; Inappropriate Speech: $\mathrm{t}=0.008, P=0.994)$.

Results from the RBS-R Total score were not significant $(\mathrm{N}=9, \mathrm{t}=-0.791 ; P=0.432)$. However, analyses were performed on the RBS-R subscales and significant improvement was found on the Restricted Behavior subscale $(\mathrm{N}=9 ; \mathrm{t}=-2.077 ; P=0.042)$. Again, when 'phase' (order) was added as a third variable, the three-way interaction was not significant indicating that the significant time $x$ group interaction is not a function of treatment order. Participants also had a higher baseline RBS-R Restrictive Behavior scores at phase 1 than the placebo participants, but after adding the baseline values of the RBS-R Restricted Behavior subscale to the model, the interaction remains significant and is largely unchanged $(\mathrm{t}=-2.107$; $P=0.040)$. Results from the other RBS-R subscales were not statistically significant (Stereotyped Behavior: $\mathrm{t}=-0.269$, $P=0.789$; Self-Injurious Behavior: $\mathrm{t}=-1.896, \quad P=0.063$; Compulsive Behavior: $\mathrm{t}=0.888, P=0.378$; Ritualistic Behavior: $\mathrm{t}=-0.192, P=0.848$; Sameness: $\mathrm{t}=0.005, P=0.996$ ). 


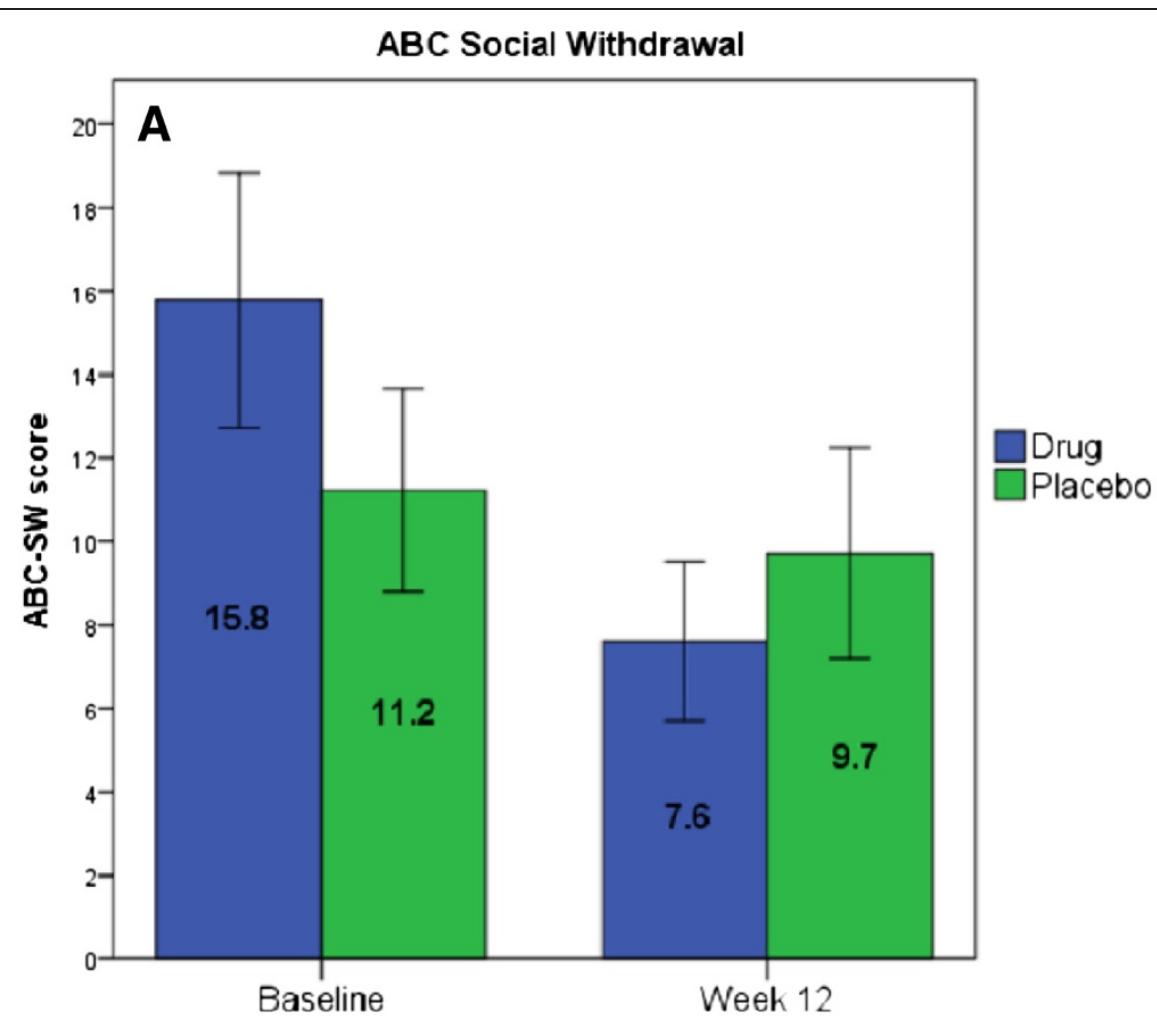

Mean Change in ABC Social Withdrawal

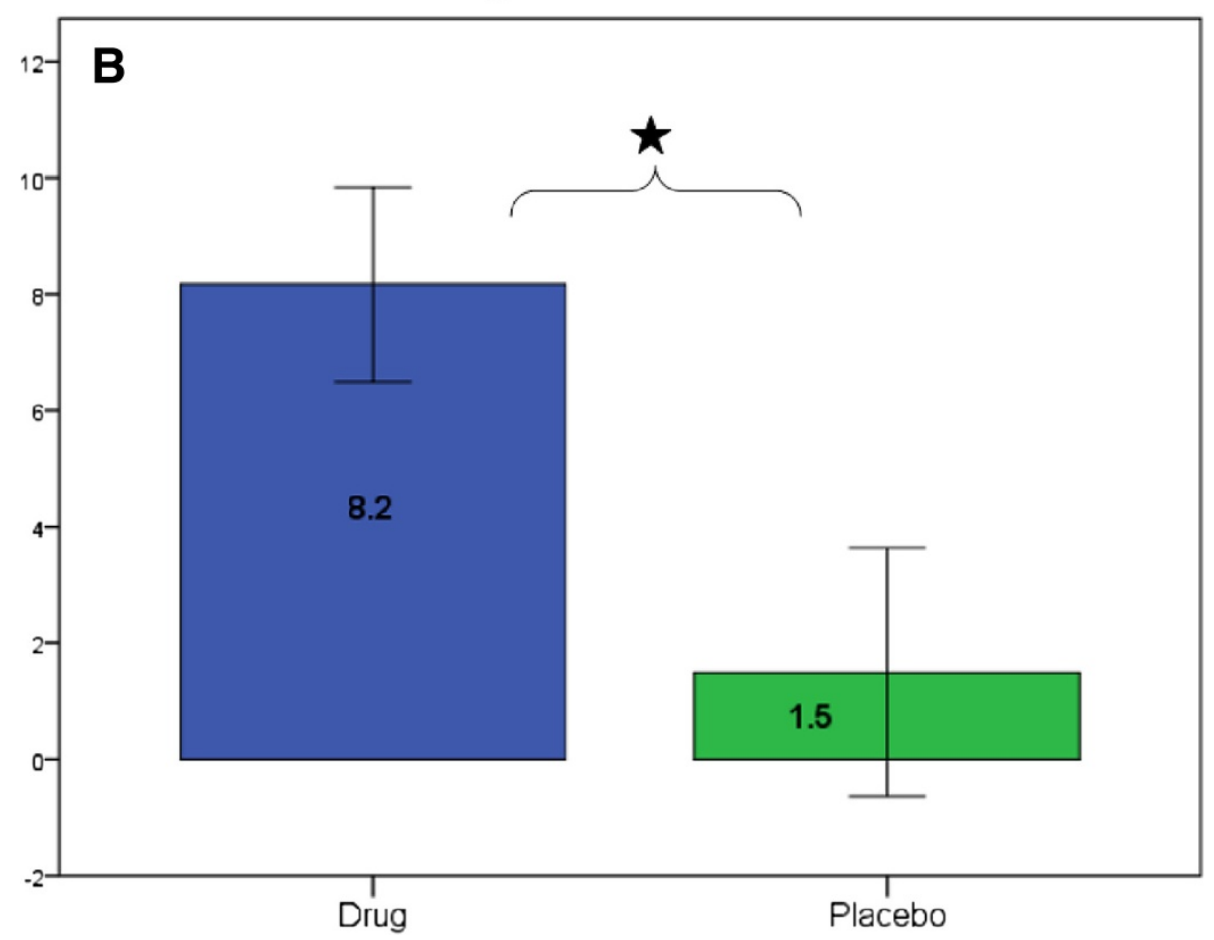

Figure 1 ABC-SW score between baseline and week 12 of drug or placebo. (A) Change in ABC-SW score between baseline and week 12 of drug or placebo for 9 subjects. In this and all subsequent figures, treatment condition (drug versus placebo) was combined across treatment phases. Error bars $= \pm 1 \mathrm{SE}$. (B) Mean change in ABC-SW score between baseline and week 12 of drug or placebo. $P=0.040$; error bars $= \pm 1 \mathrm{SE}$. ABC-SW = Aberrant Behavior Checklist Social Withdrawal subscale; SE = standard error. The star reflects the $p$ value and notes the significance. 

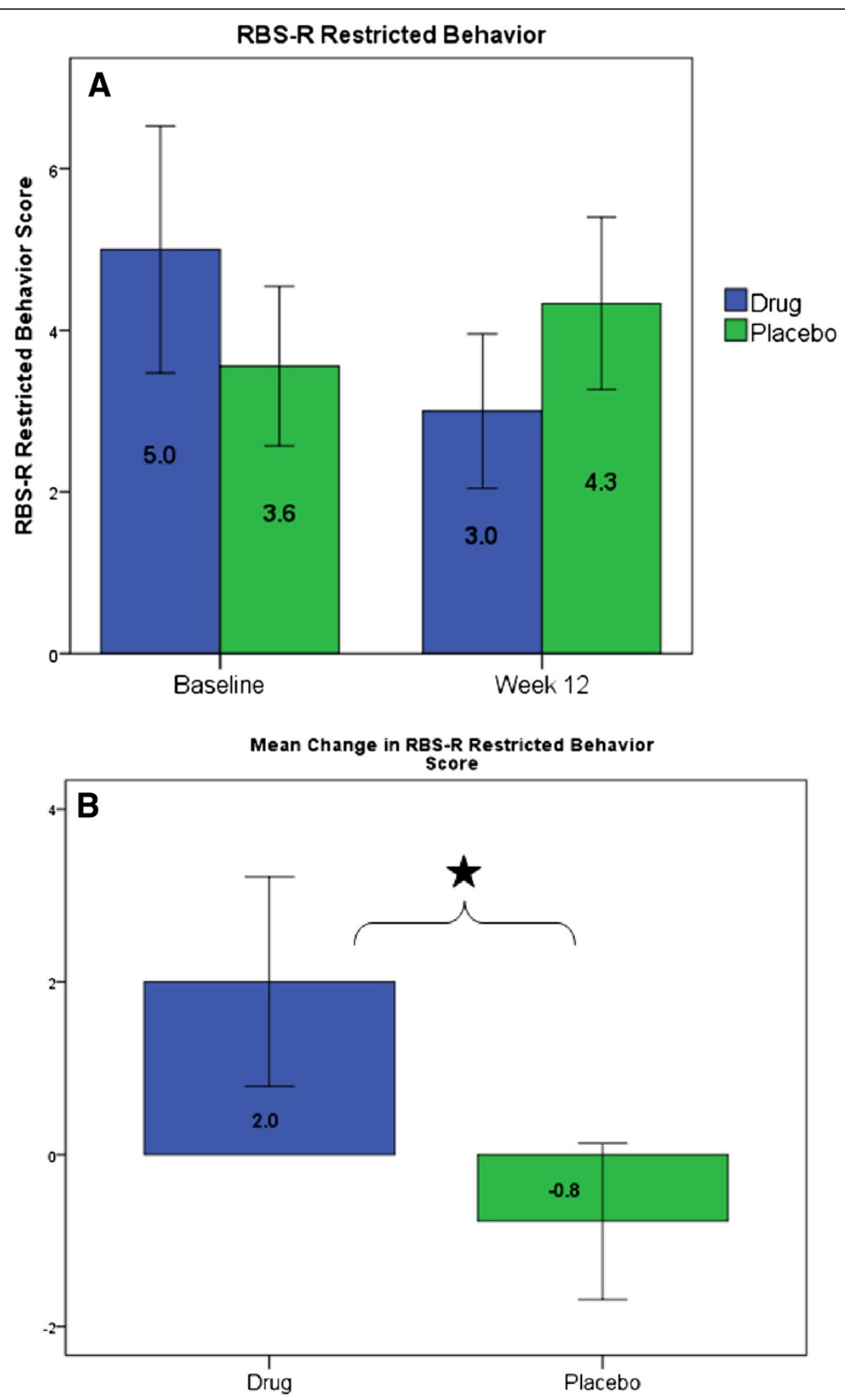

Figure 2 RBS-R Restricted Behavior score between baseline and week 12 of drug or placebo. (A) Change in RBS-R Restricted Behavior score between baseline and week 12 of drug or placebo. (B) Mean change in RBS-R Restricted Behavior score between baseline and week 12 of drug or placebo. $P=0.042$; error bars $= \pm 1 \mathrm{SE}$. RBS-R $=$ Repetitive Behavior Scale-Revised. $\mathrm{SE}=$ standard error. The star reflects the $p$ value and notes the significance. 


\section{Discussion}

This is the first controlled treatment trial in PMS and establishes safety and preliminary evidence of benefit of IGF-1 on core symptoms of ASD. Although PMS is now recognized to be a relatively common cause of ASD, a review of the literature revealed only two published reports of medication treatment trials, one case series with intranasal insulin [36] and one case study with risperidone [37], both open label and with reported improvement. In the intranasal insulin study, 6 children received up to 12 months of treatment with improvement based on sum of scores from a parental questionnaire in most domains, including cognitive, speech and language, and motor skills [36]. Insulin was hypothesized in these cases to improve neuronal function by increasing CNS glucose uptake and enhancing synaptic plasticity via glutamatergic receptors. Results from the case study with risperidone were similarly optimistic but equally uncontrolled: an 18year-old girl with PMS was treated with risperidone $0.5 \mathrm{mg}$ twice daily with significant improvement on the Clinical Global Impression Scale (CGI; [38]) in anxiety, aggression, and insomnia after 1 month that was sustained after 6 months. The hypothesized mechanism of action of risperidone in SHANK3 deficiency was to promote Nmethyl-D-aspartate (NMDA) transmission via dopamine 2 receptor blockade. However, studies in Shank3 deficient mice indicate that reduced basal neurotransmission at glutamatergic synapses may be $\alpha$-amino-3-hydroxy-5methyl-4-isoxazolepropionic acid (AMPA) receptor mediated [20].

To date, few pharmacological treatments in ASD have been developed based on neurobiological strategies. Most trials have employed etiologically heterogeneous samples and targeted associated symptoms. More recently, genetic discovery and model systems have led to important opportunities for developing novel, potentially diseasemodifying therapeutics. This study is based on preclinical evidence showing that IGF-1 reversed deficits in mouse and neuronal models of SHANK3 deficiency. The results now provide preliminary evidence of efficacy with IGF-1 in a clinical sample of children with PMS. Recent examples of a similar approach to treatment development are the large-scale clinical trials currently underway in fragile X syndrome (FXS), Rett syndrome, and tuberous sclerosis, all known causes of ASD. The SHANK3/glutamate signaling pathway is highly relevant to various forms of ASD $[18,19]$ and the link between deficits in synapse function and ASD suggest that treatment with IGF-1 may have implications for ASD caused by disruptions in common underlying pathways. Importantly, the first evidence of the efficacy of IGF-1 in an ASD-related syndrome has already emerged in Rett syndrome [23].

Despite the promise of these findings, several weaknesses must be acknowledged. For example, the small sample challenges our ability to generalize results to a broader population of children with PMS. The resulting decrease in statistical power did not compromise the significance of our findings but it is possible that the effect size may not be upheld in a larger sample. In addition, we showed that when patients received IGF-1 they were significantly more likely to report AEs and this may have introduced bias and contributed to the caregivers' anticipation of benefit. Such challenges are inherent to using caregiver reports as outcome measures. Further, while patients were more likely to report AEs while on IGF-1, the nature of AEs was similar between treatment groups. Lastly, crossover trial designs carry risks of treatment order effects. We provided a 4-week wash-out period to minimize this risk and evaluated the differential effect of treatment over time in the context of order to show that there was no significant effect of treatment order. We chose to use this design because PMS is a rare disease without available treatments and wanted to ensure that all participants were afforded the opportunity to receive active medication; the cost of IGF-1 prohibited an open label extension trial.

\section{Conclusions}

Results from this study are novel and of broad interest for a number of important reasons. First, PMS, while considered a rare disorder, is now known to be a more common, and highly penetrant cause of ASD [39]. As such, there is significant interest in the SHANK3 gene as genetic discovery and functional analysis of model systems continue to aid in our understanding of the neurobiology of ASD. Second, this is a translational clinical trial based on prior work in mice that demonstrates IGF-1 to reverse electrophysiological and motor learning deficits [21]. Third, an independent group has demonstrated a reversal of synaptic deficits with IGF-1 in neurons derived from induced pluripotent stem cells of patients with PMS [21]. Fourth, there is now additional independent clinical evidence of the efficacy of IGF-1 in Rett syndrome to generate interest in this compound. Finally, we have shown benefits with IGF-1 on core symptoms of ASD, suggesting a potentially disease-modifying effect. Of course, these positive findings must be interpreted with caution given the small sample size. With its limitations, the present study nevertheless contributes the first evidence of the safety and efficacy of IGF-1 in PMS from the first controlled treatment trial in the field. Results from this pilot are intended to facilitate larger studies that will more definitively inform efficacy.

\section{Abbreviations}

ABC: Aberrant Behavior Checklist; ADI-R: Autism Diagnostic Interview-Revised; ADOS-G: Autism Diagnostic Observation Schedule-Generic; AE: adverse event; AMPA: a-amino-3-hydroxy-5-methyl-4-isoxazolepropionic acid; ASD: autism spectrum disorder; BBB: blood-brain barrier; CGI: Clinical Global Impression Scale; CNS: central nervous system; DSM-5: Diagnostic and Statistical Manual for Mental Disorders; FDA: Food and Drug Administration; ID: intellectual disability; FXS: fragile X syndrome; IGF-1: insulin-like 
growth factor-1; IGFBP-3: IGF binding protein-3; IRB: Institutional Review Board; NMDA: N-methyl-D-aspartate; PMS: Phelan-McDermid syndrome; rhIGF-1: recombinant human insulin-like growth factor-1; RBS-R: Repetitive Behavior Scale-Revised; SAE: serious adverse event; SMURF: Safety and Monitoring Uniform Report Form

\section{Competing interests}

The Icahn School of Medicine at Mount Sinai and Dr. Joseph Buxbaum hold a shared patent for insulin-like growth factor-1 in the treatment of Phelan-McDermid syndrome. No non-financial conflicts of interest exist for any of the authors.

\section{Authors' contributions}

AK, LB, and ATW participated in study design, data collection, data analysis, and manuscript preparation. $\Pi T$ participated in data collection, data analysis, and manuscript preparation. DH, YF and DG participated in data collection and manuscript preparation. RR participated in study design, data analysis, and manuscript preparation. WC participated in data analysis. LS and JDB participated in study design and manuscript preparation. All authors read and approved the manuscript.

\section{Acknowledgments}

This work was supported by grants from the Beatrice and Samuel A Seaver Foundation and the National Institutes of Health (NIMH grant R34 MH100276-01 to AK). We would like to thank the Phelan-McDermid Syndrome Foundation for their support disseminating information about the trial - more information about PMS can be found through the Foundation at www.22q13.org or the Seaver Autism Center at www.shank3gene.org. We would also like to express our gratitude to the many families that work closely with us to better understand neurodevelopmental disability and a special thanks to the nine children and families who participated in this trial.

\section{Author details}

${ }^{1}$ Seaver Autism Center for Research and Treatment, Icahn School of Medicine at Mount Sinai, One Gustave L Levy Place, Box 1230, New York, NY 10029, USA. ${ }^{2}$ Friedman Brain Institute, New York, NY, USA. ${ }^{3}$ Mindich Child Health Institute, New York, NY, USA. ${ }^{4}$ Departments of Psychiatry, New York, NY, USA. ${ }^{5}$ Departments of Pediatrics, New York, NY, USA. ${ }^{6}$ Departments of Neuroscience, New York, NY, USA. 'Departments of Neurology, New York, NY, USA. ${ }^{8}$ Departments of Genetics and Genomic Sciences, New York, NY, USA. ${ }^{9}$ Departments of Endocrinology and Diabetes, New York, NY, USA. ${ }^{10}$ Icahn School of Medicine at Mount Sinai, New York, NY, USA.

${ }^{11}$ Department of Psychology, St John's University, New York, NY, USA.

${ }^{12}$ Department of Psychiatry, Rush University Medical Center, Chicago, IL, USA.

Received: 25 June 2014 Accepted: 20 November 2014

Published: 12 December 2014

\section{References}

1. Durand CM, Betancur C, Boeckers TM, Bockmann J, Chaste P, Fauchereau F, Nygren G, Rastam M, Gillberg IC, Anckarsater H, Sponheim E, Goubran-Botros H, Delorme R, Chabane N, Mouren-Simeoni MC, de Mas P, Bieth E, Roge B, Heron D, Burglen L, Gillberg C, Leboyer M, Bourgeron T: Mutations in the gene encoding the synaptic scaffolding protein SHANK3 are associated with autism spectrum disorders. Nat Genet 2007, 39(1):25-27.

2. Gauthier J, Spiegelman D, Piton A, Lafreniere RG, Laurent S, St-Onge J, Lapointe L, Hamdan FF, Cossette P, Mottron L, Fombonne E, Joober R, Marineau C, Drapeau P, Rouleau GA: Novel de novo SHANK3 mutation in autistic patients. Am J Med Genet B Neuropsychiatr Genet 2009, 150B(3):421-424.

3. Marshall CR, Noor A, Vincent JB, Lionel AC, Feuk L, Skaug J, Shago M, Moessner R, Pinto D, Ren Y, Thiruvahindrapduram B, Fiebig A, Schreiber S, Friedman J, Ketelaars CE, Vos YJ, Ficicioglu C, Kirkpatrick S, Nicolson R, Sloman L, Summers A, Gibbons CA, Teebi A, Chitayat D, Weksberg R, Thompson A, Vardy C, Crosbie V, Luscombe S, Baatjes R, et al: Structural variation of chromosomes in autism spectrum disorder. Am J Hum Genet 2008, 82(2):477-488.

4. Moessner R, Marshall CR, Sutcliffe JS, Skaug J, Pinto D, Vincent J, Zwaigenbaum L, Fernandez B, Roberts W, Szatmari P, Scherer SW: Contribution of SHANK3 mutations to autism spectrum disorder. Am J Hum Genet 2007, 81(6):1289-1297.
5. Boeckers TM: The postsynaptic density. Cell Tissue Res 2006, 326(2):409-422.

6. Bonaglia MC, Giorda R, Beri S, De Agostini C, Novara F, Fichera M, Grillo L, Galesi O, Vetro A, Ciccone R, Bonati MT, Giglio S, Guerrini R, Osimani S, Marelli S, Zucca C, Grasso R, Borgatti R, Mani E, Motta C, Molteni M, Romano C, Greco D, Reitano S, Baroncini A, Lapi E, Cecconi A, Arrigo G, Patricelli $M G$, Pantaleoni $C$, et al: Molecular mechanisms generating and stabilizing terminal 22q13 deletions in 44 subjects with Phelan/ McDermid syndrome. PLoS Genet 2011, 7(7):e1002173.

7. Bonaglia MC, Giorda R, Mani E, Aceti G, Anderlid BM, Baroncini A, Pramparo T, Zuffardi O: Identification of a recurrent breakpoint within the SHANK3 gene in the 22q13.3 deletion syndrome. J Med Genet 2006, 43(10):822-828.

8. Denayer A, Van Esch H, de Ravel T, Frijns JP, Van Buggenhout G, Vogels A, Devriendt K, Geutjens J, Thiry P, Swillen A: Neuropsychopathology in 7 patients with the $22 q 13$ deletion syndrome: presence of bipolar disorder and progressive loss of skills. Mol Syndromol 2012, 3(1):14-20.

9. Dhar SU, del Gaudio D, German JR, Peters SU, Ou Z, Bader PI, Berg JS, Blazo M, Brown CW, Graham BH, Grebe TA, Lalani S, Irons M, Sparagana S, Williams M, Phillips JA 3rd, Beaudet AL, Stankiewicz P, Patel A, Cheung SW, Sahoo T: 22q13.3 deletion syndrome: clinical and molecular analysis using array CGH. Am J Med Genet A 2010, 152A(3):573-581.

10. Jeffries AR, Curran S, Elmslie F, Sharma A, Wenger S, Hummel M, Powell J: Molecular and phenotypic characterization of ring chromosome 22. Am J Med Genet A 2005, 137(2):139-147.

11. Koolen DA, Reardon W, Rosser EM, Lacombe D, Hurst JA, Law CJ, Bongers EM, van Ravenswaaij-Arts CM, Leisink MA, van Kessel AG, Veltman JA, de Vries BB: Molecular characterisation of patients with subtelomeric $22 q$ abnormalities using chromosome specific array-based comparative genomic hybridisation. Eur J Hum Genet 2005, 13(9):1019-1024.

12. Luciani JJ, de Mas P, Depetris D, Mignon-Ravix C, Bottani A, Prieur M, Jonveaux P, Philippe A, Bourrouillou G, de Martinville B, Delobel B, Vallee L, Croquette MF, Mattei MG: Telomeric 22q13 deletions resulting from rings, simple deletions, and translocations: cytogenetic, molecular, and clinical analyses of 32 new observations. J Med Genet 2003, 40(9):690-696.

13. Manning MA, Cassidy SB, Clericuzio C, Cherry AM, Schwartz S, Hudgins L, Enns GM, Hoyme HE: Terminal 22q deletion syndrome: a newly recognized cause of speech and language disability in the autism spectrum. Pediatrics 2004, 114(2):451-457.

14. Nesslinger NJ, Gorski JL, Kurczynski TW, Shapira SK, Siegel-Bartelt J, Dumanski JP, Cullen RF Jr, French BN, McDermid HE: Clinical, cytogenetic, and molecular characterization of seven patients with deletions of chromosome 22q13.3. Am J Hum Genet 1994, 54(3):464-472.

15. Phelan MC, Rogers RC, Saul RA, Stapleton GA, Sweet K, McDermid H, Shaw SR, Claytor J, Willis J, Kelly DP: 22q13 deletion syndrome. Am J Med Genet 2001, 101(2):91-99.

16. Philippe A, Boddaert N, Vaivre-Douret L, Robel L, Danon-Boileau L, Malan V de Blois MC, Heron D, Colleaux L, Golse B, Zilbovicius M, Munnich A: Neurobehavioral profile and brain imaging study of the $22 q 13.3$ deletion syndrome in childhood. Pediatrics 2008, 122(2):e376-e382.

17. Soorya L, Kolevzon A, Zweifach J, Lim T, Dobry Y, Schwartz L, Frank Y, Wang AT, Cai G, Parkhomenko E, Halpern D, Grodberg D, Angarita B, Willner JP, Yang A, Canitano R, Chaplin W, Betancur C, Buxbaum JD: Prospective investigation of autism and genotype-phenotype correlations in 22q13 deletion syndrome and SHANK3 deficiency. Molecular Autism 2013, 4(1):18.

18. Darnell JC: Defects in translational regulation contributing to human cognitive and behavioral disease. Curr Opin Genet Dev 2011, 21(4):465-473.

19. Sakai Y, Shaw CA, Dawson BC, Dugas DV, Al-Mohtaseb Z, Hill DE, Zoghbi HY: Protein interactome reveals converging molecular pathways among autism disorders. Sci Trans/ Med 2011, 3(86):86ra49.

20. Bozdagi O, Sakurai T, Papapetrou D, Wang X, Dickstein DL, Takahashi N, Kajiwara Y, Yang M, Katz AM, Scattoni ML, Harris MJ, Saxena R, Silverman JL, Crawley JN, Zhou Q, Hof PR, Buxbaum JD: Haploinsufficiency of the autism-associated Shank3 gene leads to deficits in synaptic function, social interaction, and social communication. Molecular Autism 2010, 1(1):15.

21. Bozdagi O, Tavassoli T, Buxbaum JD: Insulin-like growth factor-1 rescues synaptic and motor deficits in a mouse model of autism and developmental delay. Mol Autism 2013, 4(1):9.

22. Marchetto MC, Carromeu C, Acab A, Yu D, Yeo GW, Mu Y, Chen G, Gage FH, Muotri AR: A model for neural development and treatment of Rett syndrome using human induced pluripotent stem cells. Cell 2010, 143(4):527-539. 
23. Jou RJ, Mateljevic N, Kaiser MD, Sugrue DR, Volkmar FR, Pelphrey KA: Structural neural phenotype of autism: preliminary evidence from a diffusion tensor imaging study using tract-based spatial statistics. AJNR Am J Neuroradiol 2011, 32(9):1607-1613.

24. Bakhtiari R, Zurcher NR, Rogier O, Russo B, Hippolyte L, Granziera C, Araabi BN, Nili Ahmadabadi M, Hadjikhani N: Differences in white matter reflect atypical developmental trajectory in autism: A Tract-based Spatial Statistics study. Neurolmage Clinical 2012, 1(1):48-56.

25. Altman NR, Bernal B: Brain activation in sedated children: auditory and visual functional MR imaging. Radiology 2001, 221(1):56-63.

26. Bernal B, Altman NR: Speech delay in children: a functional MR imaging study. Radiology 2003, 229(3):651-658.

27. Ederberg S, Westerlind A, Houltz E, Svensson SE, Elam M, Ricksten SE: The effects of propofol on cerebral blood flow velocity and cerebral oxygen extraction during cardiopulmonary bypass. Anesth Analg 1998, 86(6):1201-1206.

28. Aman MG, Singh NN, Stewart AW, Field CJ: The aberrant behavior checklist: a behavior rating scale for the assessment of treatment effects. Am J Ment Defic 1985, 89(5):485-491.

29. Bodfish JW, Symons FJ, Parker DE, Lewis MH: Varieties of repetitive behavior in autism: comparisons to mental retardation. $J$ Autism Dev Disord 2000, 30(3):237-243.

30. Mullen EM: Mullen Scales of Early Learning. Circle Pines, MN: American Guidance Service; 1995.

31. Roid GH, Miller L: Leiter International Performance Scale-Revised. Wood Dale, IL: Stoelting Co.; 1997.

32. Sparrow SS, Cicchetti DV, Balla DA: Vineland-II Survey Forms Manual (Vineland Adaptive Behavior Scales). 2nd edition. Minneapolis, MN: AGS Publishing; 2005

33. Lord C, Risi S, Lambrecht L, Cook EH Jr, Leventhal BL, DiLavore PC, Pickles A, Rutter M: The Autism Diagnostic Observation Schedule-Generic: a standard measure of social and communication deficits associated with the spectrum of autism. J Autism Dev Disord 2000, 30(3):205-223.

34. Lord C, Rutter M, Le Couteur A: Autism Diagnostic Interview-Revised: a revised version of a diagnostic interview for caregivers of individuals with possible pervasive developmental disorders. J Autism Dev Disord 1994, 24(5):659-685.

35. American Psychiatric Association: Diagnostic and statistical manual of mental disorders. 5th edition. Arlington, VA: American Psychiatric Publishing; 2013.

36. Schmidt H, Kern W, Giese R, Hallschmid M, Enders A: Intranasal insulin to improve developmental delay in children with 22q13 deletion syndrome: an exploratory clinical trial. J Med Genet 2009, 46(4):217-222.

37. Pasini A, D'Agati E, Casarelli L, Curatolo P: Dose-dependent effect of risperidone treatment in a case of 22q13.3 deletion syndrome. Brain Dev 2010, 32(5):425-427.

38. Guy W: Assessment manual for psychopharmacology-revised. In U.S. Department of Health, Education, and Welfare, Public Health Service, Alcohol, Drug Abuse, and Mental Health Administration, NIMH Psychopharmacology Research Branch, Division of Extramural Research Programs. Rockville, MD: DHEW Publication Number ADM 76338; 1976:218-222.

39. Betancur C, Buxbaum JD: SHANK3 haploinsufficiency: a 'common' but underdiagnosed highly penetrant monogenic cause of autism spectrum disorders. Mol Autism 2013, 4(1):17.

doi:10.1186/2040-2392-5-54

Cite this article as: Kolevzon et al:: A pilot controlled trial of insulin-like growth factor-1 in children with Phelan-McDermid syndrome. Molecular Autism 2014 5:54.

\section{Submit your next manuscript to BioMed Central and take full advantage of:}

- Convenient online submission

- Thorough peer review

- No space constraints or color figure charges

- Immediate publication on acceptance

- Inclusion in PubMed, CAS, Scopus and Google Scholar

- Research which is freely available for redistribution

Submit your manuscript at www.biomedcentral.com/submit
C Biomed Central 